\title{
Effect of the amino acid alanine on glucagon secretion in non-diabetic and type 1 diabetic subjects during hyperinsulinaemic euglycaemia, hypoglycaemia and post-hypoglycaemic hyperglycaemia
}

\author{
F. Porcellati • S. Pampanelli • P. Rossetti • \\ N. Busciantella Ricci • S. Marzotti • P. Lucidi • \\ F. Santeusanio • G. B. Bolli • C. G. Fanelli
}

Received: 3 June 2006 / Accepted: 25 September 2006 / Published online: 12 December 2006

(C) Springer-Verlag 2006

\begin{abstract}
Aims/hypothesis The aim of our study was to establish whether the well-known defective or absent secretion of glucagon in type 1 diabetes in response to hypoglycaemia is selective or includes lack of responses to other stimuli, such as amino acids.

Materials and methods Responses of glucagon to hypoglycaemia were measured in eight patients with type 1 diabetes and six non-diabetic subjects during hyperinsulinaemic (insulin infusion $0.5 \mathrm{mU} \mathrm{kg}^{-1} \mathrm{~min}^{-1}$ ) and eu-, hypo- and hyperglycaemic clamp studies (sequential steps of plasma glucose 5.0, 2.9, 5.0,10 mmol/l). Subjects were studied on three randomised occasions with infusion of low- or high-dose alanine, or saline.

Results With saline, glucagon increased in hypoglycaemia in non-diabetic subjects but not in diabetic subjects. Glucagon increased further with low-dose $\left(181 \pm 16 \mathrm{ng} \mathrm{l}^{-1} \mathrm{~min}^{-1}\right)$ and high-dose alanine $\left(238 \pm 20 \mathrm{ng} \mathrm{l}^{-1} \mathrm{~min}^{-1}\right)$ in non-diabetic subjects, but only with high-dose alanine in diabetic subjects (area under curve $112 \pm 5 \mathrm{ng}^{-1} \mathrm{~min}^{-1}$ ). The alanine-induced glucagon increase in diabetic subjects paralleled the spontaneous glucagon response to hypoglycaemia in non-diabetic subjects not receiving alanine. The greater responses of glucagon to hypoglycaemia with alanine infusion were offset by recovery of eu- or hyperglycaemia.
\end{abstract}

F. Porcellati $\cdot$ S. Pampanelli $\cdot$ P. Rossetti $\cdot$ N. Busciantella Ricci

S. Marzotti $\cdot$ P. Lucidi · F. Santeusanio • G. B. Bolli $(\bowtie) \cdot$

C. G. Fanelli

Department of Internal Medicine, University of Perugia,

Via E. Dal Pozzo,

06126 Perugia, Italy

e-mail: gbolli@unipg.it
Conclusions/interpretation In type 1 diabetes, the usually deficient responses of glucagon to hypoglycaemia may improve after increasing the concentration of plasma amino acids. Amino acid-enhanced secretion of glucagon in response to hypoglycaemia remains under physiological control since it is regulated primarily by the ambient plasma glucose concentration. These findings might be relevant to improving counter-regulatory defences against insulininduced hypoglycaemia in type 1 diabetes.

Keywords Hypoglycaemia - Glucagon secretion · Amino acids $\cdot$ Alanine $\cdot$ Post-hypoglycaemic hyperglycaemia

\section{Abbreviation \\ iAUC incremental area under the curve}

\section{Introduction}

In humans, the response of pancreatic alpha cells and the secretion of adrenaline are the primary lines of defence against hypoglycaemia [1, 2]. The failure of glucagon levels to increase leads to more severe hypoglycaemia despite larger increases in adrenaline in non-diabetic subjects [3] and subjects with type 1 diabetes [4]. Subjects with type 1 diabetes exhibit reduced responses of glucagon to hypoglycaemia shortly after the onset of diabetes [5]. The defect is progressive and becomes total within a few years of diabetes inception [5]. This counter-regulatory defect contributes to frequent hypoglycaemia in type 1 diabetes during insulin treatment and may initiate a vicious circle of recurrent hypoglycaemia. Over time, frequent episodes of hypoglycaemia induce unawareness of hypo- 
glycaemia as well as impaired counter-regulation, which in turn predisposes to a high risk of severe hypoglycaemia in patients with type 1 diabetes [6].

More than 30 years ago, Gerich et al. were the first to propose that in type 1 diabetes the defect of alpha cells, which do not release glucagon during hypoglycaemia, is selective, since it does respond normally to other physiological stimuli of glucagon secretion, such as the amino acid arginine [7]. However, this conclusion was based on studies in which diabetic subjects were studied under conditions of relative insulin deficiency, which might have exaggerated glucagon responses to arginine. In fact, when insulin is replaced in type 1 diabetic subjects the response of glucagon to arginine is smaller $[8,9]$.

If the alpha cell defects in type 1 diabetes are in fact selective, as suggested by Gerich et al. [7], one might hypothesise that amino acid stimulation could sustain glucagon secretion not only in euglycaemia but also in response to hypoglycaemia. Only two studies have examined the responses of glucagon to hypoglycaemia during amino acid stimulation in subjects with type 1 diabetes. In one study, a mixture of amino acids was given at the end of hypoglycaemia and no effects were reported [10]. In the other study, two amino acids (alanine and glutamine) were reported to stimulate glucagon secretion during insulininduced hypoglycaemia, but responses in glucagon were present also in the placebo study [11]. Thus, at present it is not definitively established whether the alpha cell in type 1 diabetes has a defect which is selective for glucose under conditions of insulin replacement, or whether amino acid stimulation sustains the responses of glucagon to hypoglycaemia in type 1 diabetic subjects.

The aims of the present study were: (1) to establish whether, in subjects with type 1 diabetes, who usually lose responses of glucagon to hypoglycaemia, alanine first stimulates the secretion of glucagon when insulin is replaced and euglycaemia is maintained; (2) if so, to establish whether the effect extends to hypoglycaemia; and (3) to assess whether hyperglycaemia offsets the responses of glucagon to antecedent hypoglycaemia. This equates to establishing a permissive role for alanine in the restoration of physiological alpha cell responses, i.e. a role specific to changes in ambient glucose concentration rather than direct amino acid stimulation. In order to make these assessments, the results obtained in subjects with type 1 diabetes were compared with those non-diabetic subjects matched for age, gender and BMI.

\section{Subjects and methods}

Subjects Eight subjects with type 1 diabetes mellitus who were on long-term intensive insulin treatment were recruited from among those attending the outpatient Diabetes Clinic of the Department of Internal Medicine, Endocrinology and Metabolism of the University of Perugia (Table 1). At the time of the study, all diabetic subjects were free of any detectable microangiopathic complication and were negative on screening for autonomic neuropathy, as judged on the basis of a standard battery of cardiovascular tests [12]. A group of six healthy, nondiabetic volunteers were also studied as a control group (Table 1).

Design of the study The study was approved by the local ethics committee and carried out after written informed consent had been given by all subjects. All non-diabetic and diabetic volunteers were studied on three occasions in random order at intervals of 2 or 3 weeks. In diabetic subjects, care was taken to avoid preprandial, postprandial and nocturnal blood glucose concentrations $<4.0 \mathrm{mmol} /$ $1(72 \mathrm{mg} / \mathrm{dl})$ over the week prior to studies, by intensifying blood glucose monitoring and telephone contacts, as previously reported [13]. On the day prior to studies, patients had their usual insulin treatment with the last s.c. NPH insulin injection at $\sim 23.00 \mathrm{~h}$, which was chosen on the basis of experience with nocturnal $(03.00 \mathrm{~h})$ and fasting blood glucose over the previous 2 weeks. On the morning of the studies, patients were admitted to the General Clinical Research Centre of the Department of Internal Medicine at $\sim 07.00 \mathrm{~h}$. A hand vein of the non-dominant arm was cannulated retrogradely and maintained in a hot box $\left(\sim 60^{\circ} \mathrm{C}\right)$ for sampling of arterialised venous blood [14]. A superficial vein of the ipsilateral arm was also cannulated for infusion of insulin and glucose (see below). The two veins were maintained patent by means of $0.9 \% \mathrm{NaCl}$ infusion $(0.5 \mathrm{ml} / \mathrm{min})$. At $\sim 07: 30 \mathrm{~h}$, an i.v. infusion of human regular insulin was begun in a feedback fashion to maintain plasma glucose at $5.5 \mathrm{mmol} / \mathrm{l}(100 \mathrm{mg} / \mathrm{dl})$, as described previously [15], and continued until $11.00 \mathrm{~h}$ (time $0 \mathrm{~min}$ ).

Table 1 Clinical characteristics of subjects

\begin{tabular}{lll}
\hline & $\begin{array}{l}\text { Non-diabetic } \\
\text { subjects }\end{array}$ & Diabetic subjects \\
\hline Sex & $\begin{array}{l}\text { Three male, three } \\
\text { female }\end{array}$ & $\begin{array}{l}\text { Four male, four } \\
\text { female }\end{array}$ \\
Age (years) & $32 \pm 8(27-49)$ & $30 \pm 11(18-52)$ \\
$\mathrm{BMI}\left(\mathrm{kg} / \mathrm{m}^{2}\right)$ & $22 \pm 2.7(18-24)$ & $23.4 \pm 4.3(20-30)$ \\
$\mathrm{HbA}_{1 \mathrm{c}}(\%)$ & $5.2 \pm 0.4(4.5-5.7)$ & $6.9 \pm 0.9(5.6-8.3)$ \\
Diabetes duration (years) & - & $12 \pm 12(3-43)$ \\
C-peptide (nmol/1) & $1.1 \pm 0.2$ & $0.03 \pm 0.02$ \\
\hline
\end{tabular}

Values are means \pm SD (range) 
Non-diabetic volunteers were admitted at $07.30 \mathrm{~h}$ on the day of the study. Afterwards, non-diabetic subjects were cannulated as described for diabetic subjects. Both nondiabetic and diabetic subjects were studied on three occasions by the hyperinsulinaemic and eu-, hypo- and post-hypoglycaemic hyperglycaemic clamp technique. At $09.00 \mathrm{~h}$ (time $-120 \mathrm{~min}$ ), diabetic and non-diabetic subjects were infused with L-alanine (Galenica Senese Pharmaceutical Industry, Siena, Italy), at the rate of $5.6 \mu \mathrm{mol} \mathrm{kg}{ }^{-1}$ $\min ^{-1}$ (low-dose alanine) or $28 \mu \mathrm{mol} \mathrm{kg}{ }^{-1} \min ^{-1}$ (highdose alanine) or saline until the end of the studies (250 $\mathrm{min})$. In both groups of subjects, insulin was infused i.v. at the rate of $0.5 \mathrm{mU} \mathrm{kg}^{-1} \mathrm{~min}^{-1}$ from $11.00 \mathrm{~h}$ (time $0 \mathrm{~min}$ ) until $15.10 \mathrm{~h}$ (time $250 \mathrm{~min}$ ) and glucose was infused i.v. at a variable rate to decrease plasma glucose from $5.5 \mathrm{mmol} / 1(100 \mathrm{mg} / \mathrm{dl})$ to $2.9 \mathrm{mmol} / 1(50 \mathrm{mg} / \mathrm{dl})$ by $90 \mathrm{~min}$. The hypoglycaemic plateau $(2.9 \mathrm{mmol} / \mathrm{l})$ was maintained until $130 \mathrm{~min}$. After $130 \mathrm{~min}$, in all studies the rate of glucose infusion was increased in order to restore euglycaemia $(5.5 \mathrm{mmol})$ in $20 \mathrm{~min}$ (time $150 \mathrm{~min}$ ) and maintain euglycaemia for 40 until $190 \mathrm{~min}$. Thereafter the rate of glucose infusion was increased further to produce hyperglycaemia (10 $\mathrm{mmol} / \mathrm{l})$ until the end of the study $(250 \mathrm{~min})$.

Throughout the paper, baseline, initial euglycaemia, hypoglycaemia, euglycaemia post-hypoglycaemia and hyperglycaemia denote the following time or time intervals: -120 min (baseline), 0-30 min (initial euglycaemia), 31$130 \mathrm{~min}$ (hypoglycaemia), 150-190 min (post-hypoglycaemic euglycaemia) and 191-250 min (hyperglycaemia), respectively.

In all studies, blood was drawn at regular intervals for measurement of plasma concentrations of glucose, insulin, counter-regulatory hormones (glucagon and catecholamines) and non-glucose substrates.

Analytical methods Plasma glucose was measured by means of a Beckman glucose analyser (Glucose Analyzer II; Beckman Instruments, Fullerton, CA, USA). Plasma insulin, glucagon, adrenaline, noradrenaline, glycerol, $\beta$ hydroxybutyrate, lactate and alanine were measured by previously described assays [15-17]. To remove antibodybound insulin, plasma was mixed with an equal volume of $30 \%$ polyethylene glycol immediately after blood collection in both diabetic and non-diabetic subjects [17]. Plasma levels of insulin (sensitivity $12 \mathrm{pmol} / \mathrm{l}$; intra- and interassay CV values $<3.1$ and $6 \%$, respectively) and C-peptide (sensitivity $0.033 \mathrm{nmol} / 1$; intra- and inter-assay $<3.4$ and 9.3\%, respectively) were measured by RIA (Linco Research, St Charles, MO, USA). $\mathrm{HbA}_{1 \mathrm{c}}$ was determined by high-performance liquid chromatography using a Hi-AUTO A1C, TM HA 8121 apparatus (DIC, Kyoto Daiichi, Kogaku Co., Ltd, Kyoto, Japan) (values in non-diabetic subjects $<6.1 \%$, Diabetes Control Complication Trial aligned). Plasma NEFA concentration was measured using a commercial kit (Wako NEFA C Test Kit; Wako Chemicals GmbH, Neuss, Germany).

Statistical analysis All data were subjected to repeated measures ANOVA with Huynh-Feldt adjustment for nonsphericity [18]. Post hoc comparisons (Tukey's test) were performed to pinpoint specific differences in significant interaction means. The AUC and the incremental AUC (iAUC) was calculated for hormones and substrates at the clamped initial euglycaemia (0-30 min), hypoglycaemia (90-130 min), post-hypoglycaemic euglycaemia (150$190 \mathrm{~min})$ and hyperglycaemia (210-250 $\mathrm{min}$ ) according to the trapezoidal rule (with subtraction of the basal values for iAUC) [19] and analysed by paired or unpaired Student's $t$-test as appropriate. Data in the text are given as mean $\pm \mathrm{SE}$ and were considered to be significantly different at $p<0.05$. Statistical analysis was carried out using NCSS 2004 software (Kaysville, UT, USA) [20].

\section{Results}

Plasma glucose and plasma free insulin concentrations, and glucose infusion rate (Fig. 1) Plasma glucose did not change from baseline to $0 \mathrm{~min}$ in non-diabetic subjects, with no differences between saline, low-dose and high-dose alanine studies. Following insulin infusion, plasma glucose decreased progressively to a plateau of $2.8 \pm 0.1 \mathrm{mmol} / 1$ during hypoglycaemia, with no differences between saline and alanine studies in non-diabetic and diabetic subjects $(p>0.2)$. When glucose infusion was increased to restore posthypoglycaemic euglycaemia and subsequently to produce hyperglycaemia, plasma glucose was also not different between saline and alanine studies in non-diabetic and diabetic subjects.

Average baseline and initial euglycaemia plasma free insulin values were greater in type 1 diabetic subjects than in non-diabetic subjects $(76 \pm 5$ vs $22 \pm 0.7 \mathrm{pmol} / 1, p<0.001)$. Following insulin infusion, plasma insulin increased to a plateau of $220 \mathrm{pmol} / \mathrm{l}$ between 90 and $250 \mathrm{~min}$, with no differences between saline and alanine studies in nondiabetic and diabetic subjects.

The rate of glucose infusion in hypoglycaemia in nondiabetic subjects was not different between saline $(9.1 \pm$ $\left.3.4 \mu \mathrm{mol} \mathrm{kg}{ }^{-1} \mathrm{~min}^{-1}\right)$ and low-dose alanine $(9.3 \pm 3.2 \mu \mathrm{mol}$ $\mathrm{kg}^{-1} \min ^{-1}$ ) studies, but was lower in high-dose alanine studies $\left(5 \pm 3.4 \mu \mathrm{mol} \mathrm{kg} \mathrm{min}^{-1} ; p<0.01\right)$. In diabetic subjects, the glucose infusion rate in hypoglycaemia was lower in low-dose $\left(11 \pm 3.1 \mu \mathrm{mol} \mathrm{kg} \mathrm{min}^{-1} ; p<0.05\right)$ and high-dose alanine studies $\left(4.0 \pm 2 \mu \mathrm{mol} \mathrm{kg}{ }^{-1} \mathrm{~min}^{-1} ; p<0.01\right)$ compared with saline studies $\left(17 \pm 3.6 \mu \mathrm{mol} \mathrm{kg}^{-1} \mathrm{~min}^{-1}\right.$; 

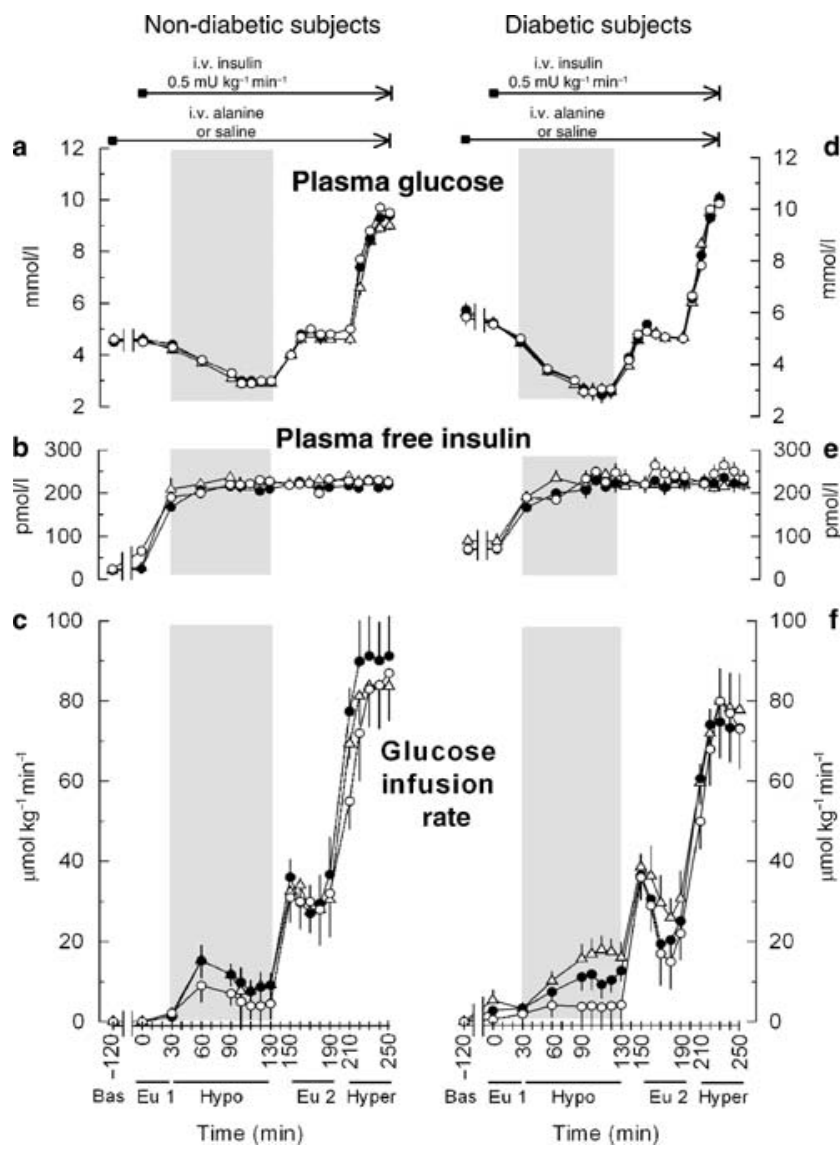

Fig. 1 Plasma glucose and free insulin concentrations and rates of glucose infusion during saline (open triangles), low-dose alanine (closed circles, $5.6 \mu \mathrm{mol} \mathrm{kg}{ }^{-1} \mathrm{~min}^{-1}$ ) and high-dose alanine (open circles, $28 \mu \mathrm{mol} \mathrm{kg}^{-1} \mathrm{~min}^{-1}$ ) studies in normal non-diabetic $(\mathbf{a}, \mathbf{b}, \mathbf{c})$ and in diabetic (d, e, f) subjects. The stippled areas depict the hypoglycaemic (Hypo) sessions (31-130 $\mathrm{min}$ ) of the studies. Eu 1 period of initial euglycaemia $(0-30 \mathrm{~min}) ; E u 2$ period of posthypoglycaemic euglycaemia (150-190 min); Hyper period of posthypoglycaemic hyperglycaemia (191-250 $\mathrm{min})$. The $p$ values refer to study $\times$ time interactions from repeated measures ANOVA. a, $p=0.41$; b, $p=0.34 ; \mathbf{c}, p=0.02 ; \mathbf{d}, p=0.37 ; \mathbf{e}, p=0.18 ; \mathbf{f}, p=0.01$

$p=0.04$ for low- vs high-dose alanine). The glucose infusion rate was not different between saline and alanine studies in hyperglycaemia in both non-diabetic and type 1 diabetic subjects.

Plasma glucagon, adrenaline and noradrenaline concentrations (Fig. 2 and Table 2) Plasma glucagon levels were similar at baseline in diabetic $(62 \pm 6 \mathrm{ng} / \mathrm{l})$ and non-diabetic subjects $(65 \pm 5 \mathrm{ng} / \mathrm{l})$, with no differences between saline and alanine studies. In saline studies, hypoglycaemia stimulated glucagon in non-diabetic subjects $(124 \pm 6 \mathrm{ng}$ $\left.\mathrm{l}^{-1} \mathrm{~min}^{-1}\right)$ but not in diabetic subjects $\left(51 \pm 5 \mathrm{ng} \mathrm{l}^{-1} \mathrm{~min}^{-1}\right.$; AUC $90-130 \mathrm{~min}, p<0.05)$. In the alanine studies, the response of glucagon was potentiated in non-diabetic and, to a lesser extent, in diabetic subjects. In non-diabetic subjects, plasma glucagon increased from baseline to $0 \mathrm{~min}$
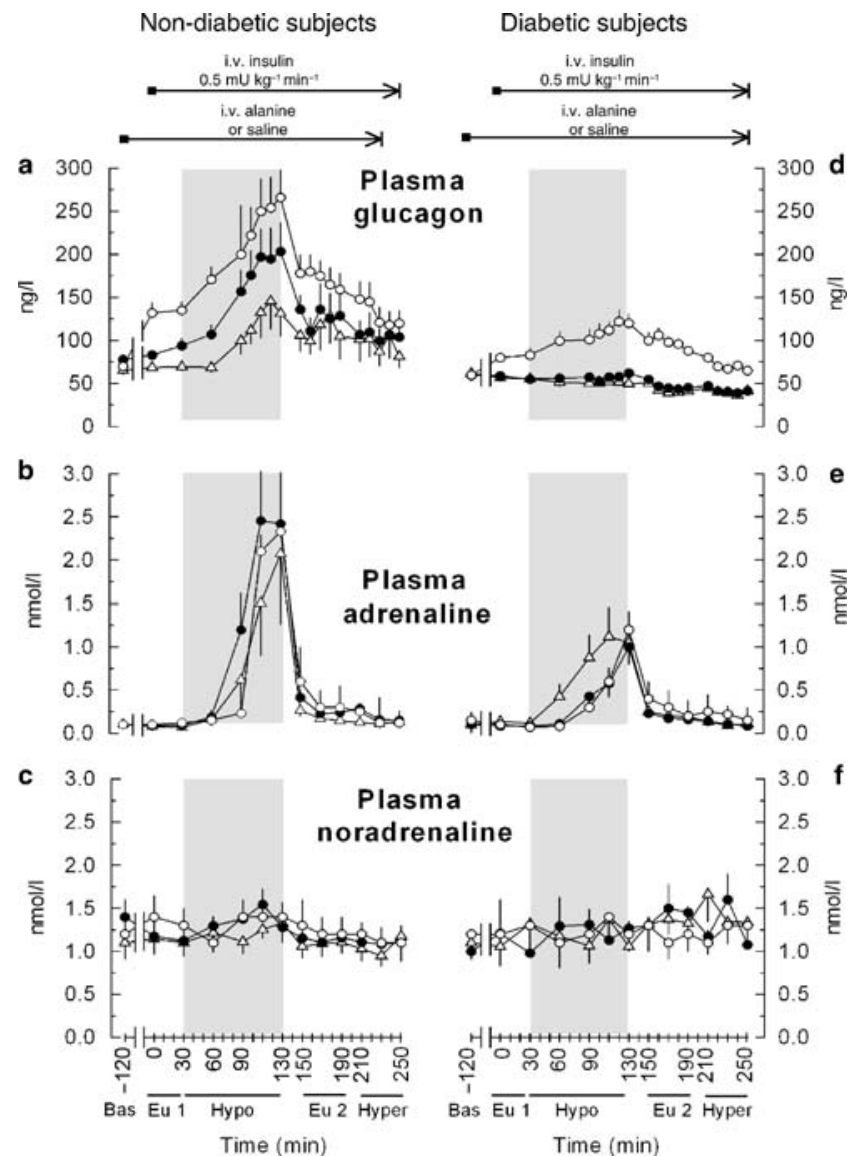

Fig. 2 Plasma glucagon, adrenaline and noradrenaline concentrations during saline (open triangles), low-dose alanine (closed circles, $5.6 \mu \mathrm{mol} \mathrm{kg}{ }^{-1} \mathrm{~min}^{-1}$ ) and high-dose alanine (open circles, $28 \mu \mathrm{mol}$ $\mathrm{kg}^{-1} \min ^{-1}$ ) studies in normal non-diabetic $(\mathbf{a}, \mathbf{b}, \mathbf{c})$ and in diabetic (d, e, f) subjects. The stippled areas depict the hypoglycaemic (Hypo) sessions (31-130 $\mathrm{min})$ of the studies. Eu 1 period of initial euglycaemia $(0-30 \mathrm{~min}) ; E u 2$ period of post-hypoglycaemic euglycaemia (150-190 min); Hyper period of post-hypoglycaemic hyperglycaemia (191-250 $\mathrm{min})$. The $p$ values indicate study $\times$ time interactions from repeated measures ANOVA. a, $p=0.01 ; \mathbf{b}, p=0.45$; c, $p=0.32 ; \mathbf{d}, p=0.03 ; \mathbf{e}, p=0.21 ; \mathbf{f}, p=0.61$

to a greater extent in high-dose $\left(132 \pm 12 \mathrm{ng}^{-1} \mathrm{~min}^{-1}\right)$ than in low-dose studies $\left(83 \pm 5 \mathrm{ng}^{-1} \mathrm{~min}^{-1}\right.$; AUC $120-0 \mathrm{~min}$, $p<0.05)$. Afterwards, glucagon continued to increase in initial euglycaemia (peak value greater with high vs lowdose alanine, $135 \pm 10$ vs $94 \pm 8.9 \mathrm{ng} / \mathrm{l}$, respectively; $p=0.02$ ) and during subsequent hypoglycaemia. The glucagon response to hypoglycaemia in non-diabetic subjects was greater in high-dose than in low-dose alanine studies (AUC 90-130 min, 238 \pm 20 vs $181 \pm 16 \mathrm{ng} \mathrm{l}^{-1} \mathrm{~min}^{-1}$, respectively; $p=0.04$ ).

In diabetic subjects the response of glucagon in initial euglycaemia to low-dose alanine was not different from the response to saline (AUC 0-30 $\mathrm{min}, 57 \pm 7$ and $52 \pm 5 \mathrm{ng} \mathrm{l}^{-1}$ $\min ^{-1}$, respectively; $p>0.2$ ), but was greater in high-dose studies $\left(81 \pm 6 \mathrm{ng} \mathrm{l}^{-1} \mathrm{~min}^{-1} ; p=0.04\right)$. In high-dose studies, the glucagon response also increased in hypoglycaemia 
Table 2 Incremental glucagon and adrenaline (incremental area under curve, iAUC) responses during initial euglycaemia $(0-30 \mathrm{~min})$ and hypoglycaemia (31-130 $\mathrm{min})$ periods

\begin{tabular}{|c|c|c|c|}
\hline & $\begin{array}{l}\text { Non-diabetic } \\
\text { subjects }\end{array}$ & $\begin{array}{l}\text { Diabetic } \\
\text { subjects }\end{array}$ & $p$ value \\
\hline \multicolumn{4}{|l|}{ Glucagon } \\
\hline \multicolumn{4}{|c|}{$\mathrm{iAUC}_{0-30 \min }\left(\mathrm{ng} \mathrm{l}^{-1} \mathrm{~min}^{-1}\right)$} \\
\hline Saline & $0.8 \pm 2$ & $-1.3 \pm 2$ & $>0.2$ \\
\hline Low-dose alanine & $3 \pm 1.5$ & $-3.7 \pm 2.5$ & 0.07 \\
\hline High-dose alanine & $11 \pm 6$ & $3 \pm 2$ & $>0.2$ \\
\hline \multicolumn{4}{|c|}{ iAUC $_{31-130 ~ m i n}\left(\mathrm{ng} \mathrm{l}^{-1} \mathrm{~min}^{-1}\right)$} \\
\hline Saline & $56 \pm 8$ & $-5.5 \pm 4.3$ & $<0.01$ \\
\hline Low-dose alanine & $109 \pm 22$ & $7.13 \pm 5.2$ & $<0.01$ \\
\hline High-dose alanine & $131 \pm 29$ & $31 \pm 5$ & 0.01 \\
\hline \multicolumn{4}{|l|}{ Adrenaline } \\
\hline \multicolumn{4}{|c|}{$\mathrm{iAUC}_{0-30 \mathrm{~min}}\left(\mathrm{mmol} \mathrm{l}^{-1} \mathrm{~min}^{-1}\right)$} \\
\hline Saline & $-0.01 \pm 0.1$ & $-0.02 \pm 0.01$ & $>0.2$ \\
\hline Low-dose alanine & $0 \pm 0.01$ & $-0.03 \pm 0.1$ & $>0.2$ \\
\hline High-dose alanine & $0.02 \pm 0.1$ & $-0.02 \pm 0.1$ & $>0.2$ \\
\hline \multicolumn{4}{|c|}{$\mathrm{iAUC}_{31-130 \mathrm{~min}}\left(\mathrm{mmol} \mathrm{l}^{-1} \mathrm{~min}^{-1}\right)$} \\
\hline Saline & $2.0 \pm 0.3$ & $1.1 \pm 0.2$ & 0.04 \\
\hline Low-dose alanine & $2.3 \pm 0.5$ & $0.9 \pm 0.2$ & 0.04 \\
\hline High-dose alanine & $2.2 \pm 0.4$ & $0.9 \pm 0.3$ & 0.03 \\
\hline
\end{tabular}

Values are means $\pm \mathrm{SE}$

(112 $\left.\pm 5 \mathrm{ng} \mathrm{l}^{-1} \mathrm{~min}^{-1}\right)$, although it remained lower than that of non-diabetic subjects in both high-dose $(p=0.01)$ and low-dose alanine studies $(p=0.04)$. Glucagon responses to high-dose alanine in hypoglycaemia were similar to those of non-diabetic subjects in the saline study $(p>0.2)$. However, when responses were examined for increments compared with pre-hypoglycaemic values, glucagon responses remained lower in diabetic subjects in high-dose alanine studies compared with non-diabetic subjects in saline studies $(p=0.04)$ (Table 2$)$. After hypoglycaemia, plasma glucagon concentration decreased in post-hypoglycaemic euglycaemia to values similar to those in initial euglycaemia, and decreased further in hyperglycaemia in the high-dose studies both in non-diabetic and diabetic subjects.

Plasma adrenaline responses to hypoglycaemia increased in both non-diabetic and diabetic subjects, with no differences among studies. However, the overall response was lower in diabetic than in non-diabetic subjects $(p=0.03)$. Compared with adrenaline, plasma noradrenaline increased less in hypoglycaemia both in non-diabetic subjects and diabetic subjects, without differences between studies $(p>0.1)$.

Plasma non-glucose substrates (Fig. 3) Plasma alanine concentrations tended to decrease slightly in saline studies in both diabetic and non-diabetic subjects, but were significantly higher in the low-dose $(0.87 \pm 0.6$ and $0.84 \pm 0.04 \mathrm{mmol} / \mathrm{l}$ in non-diabetic and diabetic subjects, respectively) and high-

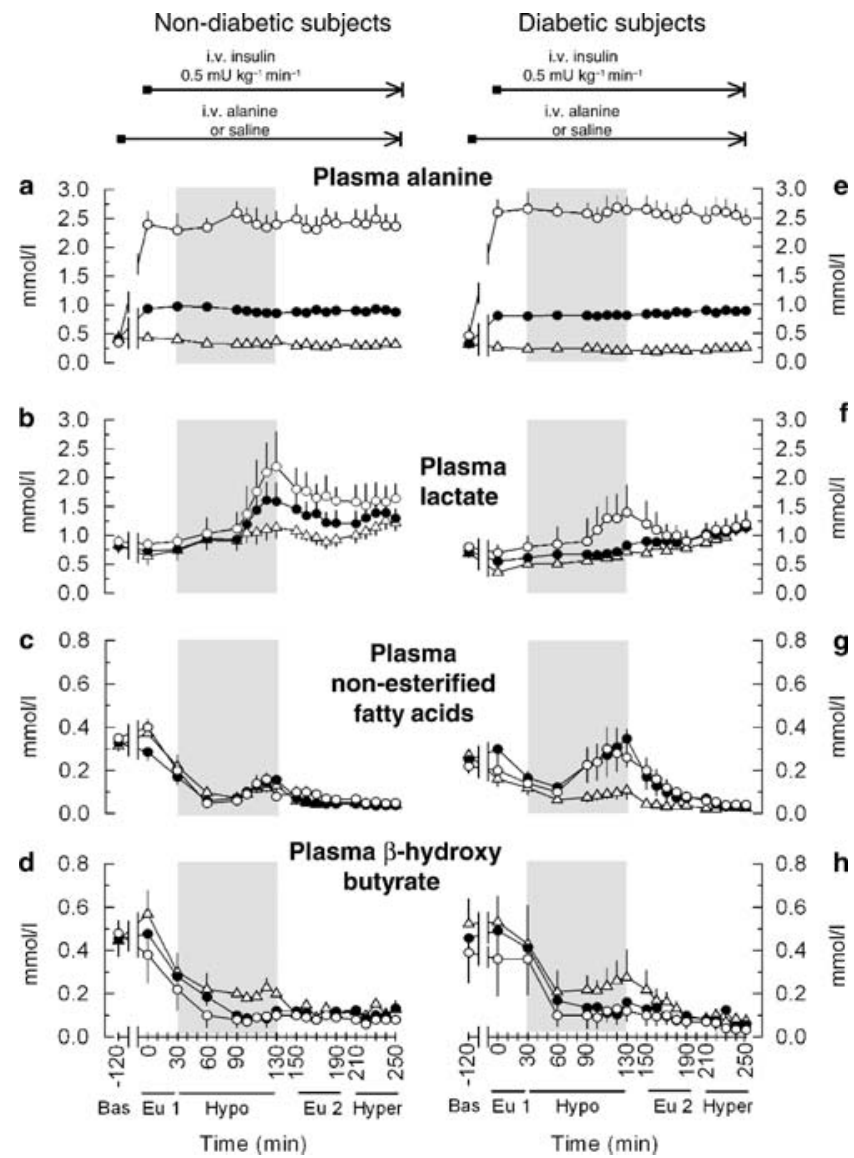

Fig. 3 Plasma alanine, lactate, NEFA and $\beta$-hydroxybutyrate concentrations during saline (open triangles), low-dose alanine (closed circles, $5.6 \mu \mathrm{mol} \mathrm{kg}{ }^{-1} \mathrm{~min}^{-1}$ ) and high-dose alanine (open circles, $\left.28 \mu \mathrm{mol} \mathrm{kg}{ }^{-1} \mathrm{~min}^{-1}\right)$ studies in normal non-diabetic $(\mathbf{a}, \mathbf{b}, \mathbf{c}, \mathbf{d})$ and in diabetic (e, f, g, h) subjects. The stippled areas depict the hypoglycaemic (Hypo) sessions (31-130 $\mathrm{min})$ of the studies. Eu 1 period of initial euglycaemia $(0-30 \mathrm{~min}) ; E u 2$ period of posthypoglycaemic euglycaemia (150-190 min); Hyper period of posthypoglycaemic hyperglycaemia (191-250 $\mathrm{min})$. The $p$ values indicate study $\times$ time interactions from repeated measures ANOVA. a, $p=0.01$; b, $p=0.02 ; \mathbf{c}, p=0.8 ; \mathbf{d}, p=0.04 ; \mathbf{e}, p<0.01 ; \mathbf{f}, p=0.03 ; \mathbf{g}, p=0.01$; h, $p=0.03$

dose alanine studies $(2.4 \pm 0.22$ and $2.6 \pm 0.21 \mathrm{mmol} / 1$ in diabetic and non-diabetic subjects, respectively; $p<0.05$ vs low-dose alanine). Plasma lactate concentration increased from baseline, with no differences between diabetic $(0.85 \pm$ $0.12 \mathrm{mmol} / \mathrm{l})$ and non-diabetic subjects $(1.0 \pm 0.15 \mathrm{mmol} / \mathrm{l}$; $p>0.2)$ in saline studies. In both alanine studies, plasma lactate concentrations increased further in non-diabetic subjects $(1.33 \pm 0.2$ and $1.7 \pm 0.25 \mathrm{mmol} / \mathrm{l}$, respectively), but only in the high-dose study in diabetic subjects $(1.1 \pm$ $0.1 \mathrm{mmol} / \mathrm{l})$. At the low dose, the values in diabetic subjects remained lower than in non-diabetic subjects $(p=0.04)$. Plasma NEFA concentrations decreased by $60 \mathrm{~min}$ in all studies. Thereafter, in non-diabetic subjects, NEFA increased, reaching a peak at 120 min which was not different $(0.12 \pm 0.03,0.15 \pm 0.04$ and $0.16 \pm 0.04 \mathrm{mmol} / 1$ for saline, low-dose alanine and high-dose alanine, respectively; 
$p>0.2$ ). In diabetic subjects, the plasma NEFA peak was higher in the alanine studies $(0.34 \pm 0.08$ and $0.30 \pm$ $0.06 \mathrm{mmol} / 1$ for the low- and high-dose groups, respectively) compared with the saline studies. In post-hypoglycaemic euglycaemia and hyperglycaemia, plasma NEFA decreased, reaching similar values by the end of the studies. Plasma $\beta$-hydroxybutyrate concentrations were suppressed throughout in all studies, both in non-diabetic and in diabetic subjects. However, in hypoglycaemia $\beta$-hydroxybutyrate was more suppressed in alanine studies $(0.09 \pm$ 0.02 and $0.09 \pm 0.03 \mathrm{mmol} / 1$ in the low- and high-dose studies in non-diabetic subjects; $0.13 \pm 0.05$ and $0.11 \pm$ $0.05 \mathrm{mmol} / \mathrm{l}$ in the low- and high-dose studies in diabetic subjects) than in saline studies $(0.19 \pm 0.03$ and $0.24 \pm$ $0.08 \mathrm{mmol} / \mathrm{l}$ in non-diabetic and diabetic subjects, respectively; $p<0.05$ for alanine studies). Afterwards, $\beta$-hydroxybutyrate concentrations remained suppressed, with no differences between studies.

\section{Discussion}

The present studies demonstrate that the pancreatic alpha cell is abnormal in subjects with type 1 diabetes both in response to insulin-induced hypoglycaemia and in response to the amino acid alanine. In response to hypoglycaemia, plasma glucagon does not increase as previously reported [7]. During alanine infusion, the response of plasma glucagon is also impaired. In fact, glucagon did not increase in the low-dose study, which elicited larger responses in nondiabetic subjects. However, the present studies indicate that type 1 diabetic subjects respond to high-dose alanine, although the response remains subnormal. Notably, the glucagon response to high-dose alanine in type 1 diabetes is initiated in euglycaemia, but then increases further in hypoglycaemia. The response of glucagon to hypoglycaemia in type 1 diabetes infused with high-dose alanine remains clearly subnormal compared with non-diabetic subjects, but these responses are normal when compared with those of non-diabetic subjects in the saline studies. Recovery of hypoglycaemia to euglycaemia and posthypoglycaemic hyperglycaemia offsets the responses of glucagon to infused alanine both in non-diabetic subjects and in subjects with and type 1 diabetes. This indicates that the amino acid enhances (normal subjects) or restores, at least in part (type 1 diabetes), the physiological glucosesensing ability of pancreatic alpha cells. The finding that type 1 diabetic subjects who lack responses of glucagon to hypoglycaemia $[1,2]$ may recover their responses to hypoglycaemia after high-dose amino acid stimulation is, to the best of our knowledge, a new observation.
In non-diabetic subjects, in the low-dose study the nearly threefold increase in the plasma concentration of alanine was associated with an increase in plasma glucagon concentration in euglycaemia and, to a larger extent, in hypoglycaemia (Fig. 2 and Table 2). The fact that after recovery of euglycaemia following hypoglycaemia the response of glucagon decreased to pre-hypoglycaemia values indicates that alanine exerts a physiological 'permissive' effect on pancreatic alpha cell responses of glucagon to ambient plasma glucose. Thus, the effect of alanine on glucagon is specific for hypoglycaemia, since it appears to be marginal in euglycaemia before and after hypoglycaemia, and fully suppressed during hyperglycaemia. Support for this interpretation derives also from the study with high-dose alanine, in which the plasma alanine concentration increased to $\sim 2.5 \mathrm{mmol} / 1$, i.e. levels commonly seen in the postprandial situation after a mixed meal in terms of total plasma amino acid concentration [21]. Compared with the low-dose alanine studies, in the highdose alanine studies the incremental effect on glucagon secretion was larger in euglycaemia but not in hypoglycaemia, indicating that a maximal stimulatory effect can be achieved with low-dose alanine. Notably, also in the highdose studies, euglycaemia and hyperglycaemia after hypoglycaemia suppressed the responses of glucagon observed in hypoglycaemia. Taken together, these observations in normal subjects indicate that: (1) a modest elevation in plasma alanine (low-dose studies) exerts a major stimulatory effect on pancreatic alpha cell secretion of glucagon in response to hypoglycaemia; (2) the larger the increase in plasma alanine (high-dose studies), the larger the glucagon response in absolute terms; and (3) during stimulation by either a low or a high dose of alanine, glucagon responses are physiologically controlled primarily by plasma glucose concentration.

It is tempting to speculate about the mechanisms of alanine (amino acid)-induced potentiation of the glucagon response to hypoglycaemia. It is likely that these include direct $[22,23]$ and indirect effects. For example, it is possible that the initially greater stimulation of beta cell function by amino acids results in a greater fall in intra-islet insulin concentration during hypoglycaemia, at least in normal non-diabetic subjects [24]. In addition, it is possible that amino acids modulate the glucose-sensing ability of alpha cells through glucagon-like peptide 1 [25].

Compared with normal, non-diabetic subjects, subjects with type 1 diabetes do not respond either to hypoglycaemia or to low-dose alanine infusion. This indicates that in type 1 diabetes the abnormality of pancreatic alpha cells is not limited to responses to hypoglycaemia but extends to other stimuli, such as the amino acid alanine, which is normally a glucagon secretagogue [23]. This finding favours the hypothesis of a non-selective defect of 
pancreatic alpha cells in type 1 diabetes. In a previous study, the amino acid arginine elicited large responses in glucagon which were absent in hypoglycaemia and since then the alpha cell defect in type 1 diabetes has been assumed to be selective [7]. However, in that study diabetic subjects were relatively insulin-deficient [7], whereas in the present studies insulin was replaced and, by current standards $\left(\mathrm{HbA}_{1 \mathrm{c}}\right)$, well controlled. Therefore, it is likely that the relative insulin deficiency was the cause of the large glucagon response to arginine in that study [7], as also indicated by other studies in which subjects with type 1 diabetes were studied under different conditions of insulin replacement $[8,9]$. The difference in prestudy glycaemic control between the previous [7] and present studies in terms of the glucagon response to insulin-induced hypoglycaemia remains uncertain, but probably does not play a role [2]. An additional difference between the previous [7] and the present study is that alanine and not arginine was infused in the present study. However, it is likely that such a difference is not relevant, since low-dose alanine in the present studies was a powerful enhancer of glucagon secretion in hypoglycaemia in non-diabetic subjects. Indeed, alanine stimulates glucagon secretion in animals [23, 26] and in humans under a variety of metabolic states [27].

In the present studies, hypoglycaemia was induced after an increase in plasma alanine. In a previous study [10] hypoglycaemia was induced before a mixture of amino acids was infused and no effect on glucagon response was found in type 1 diabetes. Although the present studies were not designed to establish the relation between the time of amino acid infusion and the glucagon responses to hypoglycaemia, it is likely that amino acids need to increase in plasma before hypoglycaemia is induced in order to elicit responses in glucagon.

The present study also indicates a positive finding in type 1 diabetes, i.e. the appearance of responses of glucagon in high-dose studies both in euglycaemia and in hypoglycaemia. Although the responses of diabetic subjects were lower than those of non-diabetic subjects with highdose alanine, it is notable that they were similar to the responses of non-diabetic subjects in saline studies (Fig. 2). One might interpret the response to high-dose alanine in diabetic subjects and the lack of response to low-dose alanine as a defect of responsiveness (sensitivity) of pancreatic alpha cells, with partial maintenance of maximal response. In line with the finding in non-diabetic subjects, the response of glucagon to high-dose alanine is specific to hypoglycaemia since the response is suppressed by recovery of plasma glucose to euglycaemia and subsequent hyperglycaemia.

The finding of the present studies that a several-fold elevation of alanine in plasma to the range of the postprandial plasma amino acid state [21] may match the responses of glucagon in type 1 diabetic subjects to those seen in non-diabetic subjects with hypoglycaemia alone opens new questions.

In a recent study [21], plasma glucagon increased in type 1 diabetic subjects in response to hypoglycaemia induced after a mixed meal. In the present studies, in the fasting state, alanine was given intravenously and responses of glucagon to hypoglycaemia qualitatively similar to those in that study [21] were observed. Although ingestion of a mixed meal [21] (which contains several amino acids, metabolites, etc.) differs from the infusion of only one amino acid in the present study, it is conceivable that, if plasma amino acids were increased to the concentration demonstrated to be effective in the present as well as previous studies [21] before hypoglycaemia, the responses of glucagon could be recovered in type 1 diabetes and counter-regulatory defences improved. Although alanine, being an amino acid, may have its own metabolic glucosesparing effect [28], its glucagon-promoter activity may account, at least in part, for the lower glucose infusion rates observed in hypoglycaemia in type 1 diabetes (Fig. 1). From this consideration it may be predicted that, in the clinical situation of impending hypoglycaemia, subjects with type 1 diabetes might improve their defences against hypoglycaemia whenever glucagon responses are stimulated by antecedent increases in plasma amino acids to the high physiological range of the postprandial situation [21]. Notably, smaller increases in plasma amino acids do not elicit an appreciable response in glucagon [29]. However, this hypothesis, as well as the relative contribution of alanine (and amino acids) per se to better counter-regulatory responses to insulin-induced hypoglycaemia versus that of the effects mediated by glucagon stimulation, remain to be tested with appropriate studies.

In the present studies, alanine had no effects on plasma adrenaline responses. Plasma adrenaline responses were lower in diabetic than in non-diabetic subjects (Fig. 2), in line with previous observations [27]. Alanine resulted in a proportionally higher plasma lactate concentration, probably as a result of metabolic inter-relationships triggered by higher plasma alanine concentrations via the Cori (glucose-lactate) and alanine-glucose cycles. An intriguing but unexplained finding is the greater plasma NEFA concentration in both alanine studies during hypoglycaemia in diabetic subjects. Although NEFA may suppress glucagon secretion [30], whether this was the case in the present studies cannot be established. However, the results of the present studies are concordant with earlier data indicating that the formation of ketone bodies is reduced by the elevation of plasma alanine, as shown in rats [31,32] and man [33]. These studies point towards a clear anti-ketogenic effect of alanine in the setting of a reciprocal relationship between alanine and ketone bodies (alanine-ketone body cycle) [33, 34]. In addition, the 
higher plasma lactate concentration seen in the alanine studies might have contributed to decreased ketone body levels because lactate has anti-ketogenic effects in vitro [35].

In conclusion, the present studies indicate that an increase in the plasma concentration of the amino acid alanine, either moderate or in the postprandial range, largely stimulates glucagon secretion in normal, nondiabetic subjects, primarily during hypoglycaemia. Because the plasma glucose concentration continues to be the primary regulator of glucagon secretion, the amino acid alanine enhances the physiological glucose-sensing ability of pancreatic alpha cells. In type 1 diabetes the sensitivity of alpha cells to alanine is markedly reduced, and a lower than normal glucagon response is seen only when a high dose of alanine is infused. Nevertheless, subjects with type 1 diabetes recover glucagon responses during high-dose alanine infusion, reproducing the response of non-diabetic subjects not receiving concurrent alanine (i.e. receiving saline alone). Additional studies are required to establish the mechanisms of the counter-regulatory role of alanine direct versus stimulation of glucagon during hypoglycaemia in type 1 diabetes, as well as the possibility of improving defences against hypoglycaemia in subjects with type 1 diabetes by elevating the plasma amino acid concentration.

Acknowledgements The authors are grateful to the Juvenile Diabetes Research Foundation International for financial support (grant 1-2005-176). The authors thank G. Cipiciani and C. Aglietti for expert laboratory assistance.

Duality of interest The authors do not have any duality of interest.

\section{References}

1. Cryer PE (1993) Glucose counterregulation: the prevention and correction of hypoglycaemia in humans. Am J Physiol 264:E144E155

2. Bolli GB, Fanelli CG (1999) Physiology of glucose counterregulation to hypoglycaemia. Endocrinol Metab Clin N Am 28:467-493

3. De Feo P, Perriello G, Torlone E et al (1991) Evidence against important catecholamine compensation for absent glucagon counterregulation. Am J Physiol 260:E203-E212

4. De Feo P, Bolli G, Perriello G et al (1983) The adrenergic contribution to glucose counterregulation in type I diabetes mellitus. Dependency on A-cell function and mediation through beta 2-adrenergic receptors. Diabetes 32:887-893

5. Bolli G, De Feo P, Compagnucci P et al (1983) Abnormal glucose counterregulation in insulin-dependent diabetes mellitus. Interaction of anti-insulin antibodies and impaired glucagon and epinephrine secretion. Diabetes 32:134-141

6. Cryer PE (1992) Iatrogenic hypoglycaemia as a cause of hypoglycaemia-associated autonomic failure in IDDM. A vicious cycle. Diabetes 41:255-260

7. Gerich JE, Langlois M, Noacco C, Karam JH, Forsham PH (1973) Lack of glucagon response to hypoglycaemia in diabetes: evidence for an intrinsic pancreatic alpha cell defect. Science 182:171-173
8. Oskarsson PR, Lins PE, Ahre B, Adamson UC (2000) Circulating insulin inhibits glucagon secretion induced by arginine in type 1 diabetes. Eur J Endocrinol 142:30-34

9. Kawamori R, Shichiri M, Kikuchi M, Yamasaki Y, Abe H (1985) The mechanism of exaggerated glucagon response to arginine in diabetes mellitus. Diabetes Res Clin Pract 1:131-137

10. Caprio S, Tamborlane WV, Zych K, Gerow K, Sherwin RS (1993) Loss of potentiating effect of hypoglycaemia on the glucagon response to hyperaminoacidemia in IDDM. Diabetes 42:550-555

11. M'bemba J, Cynober L, de Bandt P et al (2003) Effects of dipeptide administration on hypoglycaemia counterregulation in type 1 diabetes. Diabetes Metab 29:412-417

12. Ewing DJ, Clarke BF (1986) Autonomic neuropathy: its diagnosis and prognosis. Clin Endocrinol Metab 15:855-888

13. Fanelli CG, Epifano L, Rambotti AM et al (1993) Meticulous prevention of hypoglycaemia normalizes the glycemic thresholds and magnitude of most of neuroendocrine responses to, symptoms of, and cognitive function during hypoglycaemia in intensively treated patients with short-term IDDM. Diabetes 42:1683-1689

14. McGuire E, Helderman J, Tobin J, Andres R, Berman M (1976) Effects of arterial venous sampling on analysis of glucose kinetics in man. J Appl Physiol 41:565-573

15. De Feo P, Perriello G, Ventura MM et al (1986) Studies on overnight insulin requirements and metabolic clearance rate of insulin in normal and diabetic man: relevance to the pathogenesis of the dawn phenomenon. Diabetologia 29:475-480

16. Fanelli CG, De Feo P, Porcellati F et al (1992) Adrenergic mechanisms contribute to the late phase of hypoglycaemic glucose counterregulation in humans by stimulating lipolysis. J Clin Invest 89:2005-2013

17. Kuzuya H, Blix PN, Horwitz DL, Steiner DF, Rubenstein AH (1977) Determination of free and total insulin and C-peptide in insulin treated diabetics. Diabetes 26:22-29

18. Winer BJ, Brown DR, Michels KM (1991) Statistical principles in experimental design, 3rd edn. McGraw-Hill, New York

19. Le Floch JP, Escuyer P, Baudin E, Baudon D, Perlemuter L (1990) Blood glucose area under the curve. Methodological aspects. Diabetes Care 13:172-175

20. Hintze J, NCSS and PASS (2004) Number cruncher statistical systems. Kaysville, Utah. Available from http://www.ncss.com

21. Porcellati F, Pampanelli S, Rossetti P et al (2003) Counterregulatory hormone and symptom responses to insulin-induced hypoglycaemia in the postprandial state in humans. Diabetes 52:2774-2783

22. Iversen J (1971) Secretion of glucagon from the isolated, perfused canine pancreas. J Clin Invest 50:2123-2136

23. Muller WA, Faloona GR, Unger RH (1971) The effect of alanine on glucagon secretion. J Clin Invest 50:2215-2218

24. Raju B, Cryer PE (2005) Loss of the decrement in intraislet insulin plausibly explains loss of the glucagon response to hypoglycaemia in insulin-deficient diabetes. Diabetes 54:757-764

25. Dunning BE, Foley JE, Ahrén B (2005) Alpha cell function in health and disease: influence of glucagon-like peptide-1. Diabetologia 48:1700-1713

26. Kuhara T, Ikeda S, Ohneda A, Sasaki Y (1991) Effects of intravenous infusion of 17 amino acids on the secretion of GH, glucagon, and insulin in sheep. Am J Physiol 260:E21-E26

27. Wise JK, Hendler R, Felig P (1973) Evaluation of alpha-cell function by infusion of alanine in normal, diabetic and obese subjects. N Engl J Med 288:487-490

28. Felig P, Pozefsky T, Marliss E, Cahill GF Jr (1970) Alanine: key role in gluconeogenesis. Science 167:1003-1004

29. Wiethop BV, Cryer PE (1993) Glycemic actions of alanine and terbutaline in IDDM. Diabetes Care 16:1124-1130 
30. Gerich E, Langlois M, Noacco C, Lorenzi M, Karam JH, Korsham PH (1976) Comparison of the suppressive effects of elevated plasma glucose and free fatty acid levels on glucagon secretion in normal and insulin-dependent diabetic subjects. Evidence for selective alpha-cell insensitivity to glucose in diabetes mellitus. J Clin Invest 58:320-325

31. Ozand PT, Reed WD, Hawkins RL, Stevenson JH, Tildon JT, Cornblath M (1978) Effect of L-alanine infusion on gluconeogenesis and ketogenesis in the rat in vivo. Biochem J 170:583-591

32. Nosadini R, Datta H, Hodson A, Alberti KG (1980) A possible mechanism for the anti-ketogenic action of alanine in the rat. Biochem J 190:323-332
33. Nosadini R, Alberti KG, Johnston DG, Del Prato S, Marescotti C, Duner E (1981) The antiketogenic effect of alanine in normal man: evidence for an alanine-ketone body cycle. Metabolism 30:563-567

34. Nosadini R, Mcculloch A, Del Prato S, Avogaro A, Alberti KG (1982) The relationship between alanine and ketone body in vivo. Metabolism 31:1175-1178

35. Exton JH, Corbin JG, Park CR (1969) Control of gluconeogenesis in liver. IV. Differential effects of fatty acids and glucagon on ketogenesis and gluconeogenesis in the perfused rat liver. J Biol Chem 244:4095-4102 